\title{
Assessment of Nurses knowledge and Performance Regarding Infection Control in Operating Room at main Assiut University and AlEman Hospital (Suggested guidelines)
}

\author{
Salwa Abd Al Gaid Abd Al Rahman, Enas Abd Almaged Deaf \& Sahra Zaki Azer. \\ Head nurse at Assiut University Hospital Assistant University, Egypt . \\ Professor of Microbiology and Immunology, Faculty of Medicine - Assiut University, Egypt. \\ Lecturer of Adult of Nursing, Faculty of Nursing, Assiut University, Egypt.
}

\begin{abstract}
Assessment of Nurses performance Regarding Infection Control in Operating Room At main Assiut University and AlEman Hospital (Suggested guidelines). Aim: Assess of nurses performance regarding infection control in operating room at main Assiut University and Al Eman Hospitals (Suggested guidelines). Subject and methods: the study was conducted in orthopedic and general surgical department. Study design: Descriptive design was utilized. Tools: (1) Nurses knowledge questionnaire sheet, (2)Nurses practice observation checklist and development of booklet guidelines of infection control in operating room. Results: majority of nurses had good knowledge about the infection control in operating room at both hospitals. Nurses at AL Eman Hospital had unsatisfactory level of practice, half of nurses at Main Assiut University Hospital had unsatisfactory level of practice. Conclusions: nurses in operating room at both hospital have good knowledge regarding infection control in operating room, all nurses at AL Eman hospital had unsatisfactory level of practice of the principle of infection control in operating room. While half of nurses at Main Assiut University hospital had unsatisfactory level of practice.. Recommendations: the study recommended that, continued education training programs for nurses, receive vaccination before started work, activating the role of infection control team.
\end{abstract}

Key words: Assessment, Practice, Infection Control, Operating Room \& (Suggested guidelines).

\section{Introduction}

An infection is the invasion of susceptible host by potentially harmful organisms (pathogens), resulting in disease ( DeLaune \& Ladner, 2010). The operating room or suite is where the surgery will be performed. This room is a restricted area (Osborn et al., 2010). Modern operation theatre design and correctly observed aseptic procedures minimize wound contamination but infections do still occur (Burkitt et al., 2007).

Hospital -acquired infection (nosocomial infection) infection acquired during hospitalization, not present or incubating at the time of admission to hospital. In general, infections that occur more than 72 hours after admission and within 10 days are defined as nosocomial or hospital acquired (Daman, 2012).

Infection control is an essential aspect of a nurse's role in any field of practice and none more so than in preoperative environment, especially in the operating theater (Holland, 2012).

The prevention of surgical site infection (SSI) remains focus of attention because wound infections continue to be a major source of expense, morbidity, and even mortality. The significance of (SSI) is overwhelming. SSIs are the third most frequently reported nosocomial infection, accounting for $14 \%$ to $16 \%$ of nosocomial infections in hospitalized patients. Approximately $40 \%$ of nosocomial infections occurring among surgical patients (Schlossberg, 2008).

Postoperative wound infection surgical site infection is a complication of surgery with potentially consequences for the patient. The result can be delayed recovery, increased patient suffering and even death postoperative wound infection contributes to extended hospital stays and significantly increases the costs or the care. Surgical site infections are the second most common cause of hospital-associated infections according to the centers for disease control and prevention (CDC) and result in an estimated annual cost of 1.5 billion dollars (Spry, 2009).

\section{Significance of the study}

From the researcher's clinical experience it has been observed that increased surgical site infections, The researcher wanted to know the cause of the high rate of infection in wounds operations, Nurses are experiencing higher workloads than ever before due to three main reasons: increased demand for nurses, inadequate supply of nurses, and the supply of nurses is not adequate to meet the current demand, as well as to human behavior that is conditioned by education; political and economic constraints on systems. These factors are affecting on nursing knowledge and practice related to infection control in operating 
room, which lead to the necessity to assess the performance of nurses' regarding the infection control and sterile technique principles.

\section{Aim of the Study}

Assess of nurses performance regarding infection control in operating room at main Assiut University and Al Eman Hospitals (Suggested guidelines).

\section{Subject and Methods}

\section{Research design:}

Descriptive design was used to conduct this study.

\section{Setting}

The study was conducted in orthopedic and general surgical department at Main Assuit University and AlEman Algadida hospital at Assuit city.

\section{Study Subjects}

The study included all available nurses (45), (30) working in operating room at main Assiut university and 15 nurses at Al Eman Algadida hospital, who are working at the above mentioned study setting and participated in this study.

\section{Tools of the Study}

Three tools for collecting data were used in this study.

Tool [1]: Nurses knowledge questionnaire sheet Assess nurse's performance regarded infection control in operating room at main Assuit university hospital and Al Eman Algadida hospital. It includes two parts

Part I: Socio demographic data about nurses such as: age, gender, qualification, years of experience, training course, vaccination status it included 6 items developed by the researcher.

Part II : Assess nurses' knowledge about the principles of infection control in operating room in both hospitals. It included (61questions) infection control procedures developed by the researcher.

\section{Scoring system}

Three grade was given when nurses given correct and complete correct answer for information about infection control, two grade when give correct and incomplete answer, and one grade when give incorrect answer. Score, from $0<50 \%$ considered poor, from $50 \%<70 \%$ considered moderate and from $70 \%<100 \%$ good.

Tool [2]: Nurses practice observation checklist Observation checklist it was developed by the researcher based on extensive review of literature for assessing the nurse's practice regarding the infection control in operating room in both hospitals. It was consist of three parts:

\section{Part I: Preparation in operating room}

It included 96 items; hand washing included 16 items, putting overshoes (1) item, wearing cap (5) items, wear mask (8) items, surgical hand scrub (28) items, wear sterile gloves (14) items, wear sterile gown (11) items and keep aseptic technique measure (13) items.

\section{Part II: During operation}

It include protect the sterilization equipment, used sterilized linens, skin preparation on operating table, opening sterile package, solutions are used, movement of the surgical team are from sterile to sterile area. Scrubbed persons and sterile items contact only sterile area. Handling laboratory specimens, handling of sharps it included 64 items.

Part III: Post Anesthesia Care unit (recovery period)

It included restraints are removed and a sterile dressing may be applied to the incision, patency and connections of all drainage tubes and the flow rate of parenteral infusions are checked. The patient's cleanliness and dryness are given attention, and the gown is changed, removing gloves, removing cap, removing mask, removing goggles / Face shield, removing boot, removing gown, cleaning, disinfecting equipment (cidex), sterilization it included 69 items.

\section{Scoring system}

For the observational nurses practice regarding standards practice of the principle of infection control in operating room satisfactory level when executing practice of the principle of infection control in operating room. Three grade was given when the practice done complete and correctly, two grade when practice done correctly but incomplete, one grade when practice not done and zero if practice not applicable. The practice consider satisfactory level $>50 \%$, and unsatisfactory level when practice $<50 \%$.

\section{Development of booklet guidelines about} standards precaution of infection control in operating room

This booklet was prepared after extensive review of related literatures to included the standards infection control in operating room. It included hand washing, surgical hand scrubbing, correct steps to wearing personal protective equipment, application of aseptic technique principles, opening a sterile package, skin preparation, draping, cleaning, disinfection and sterilization of surgical instrument.

\section{Methods of data collection}

1. An official permission for data collection was obtained from the dean of the faculty of nursing, head of orthopedic and general surgical operation at main Assiut university Hospital and Al Eman hospital.

2. Content validity:

It was established by panel of 5 expertises who reviewed the instruments for clarity, relevance, comprehensiveness, understanding, applicability 
and easiness for administrative minor modifications were required. The content validity of this tool was checked by expert professors in fields of medicine and nursing and correction was carried out.

3. Pilot study was conducted on $10 \%$ of sample (5 nurses ) in selected setting to evaluate the applicability, clarity, reliability feasibility of the tools, estimate the time needed for data collection, and test the feasibility of conducting the research after analyzing the pilot study result, minimal modifications were done clearly and according to result of pilot study. The time taken for data collection 6 months from February 2014 until "August 2014.

4. Ethical consideration

Research proposal was approved from Ethical Committee in the faculty of nursing.

There is no risk for study nurses during application of research.

The study was follow common ethical principles in clinical research.

Oral consent was obtained from nurses that are willing to participate in study, after explaining the nature and purpose the study

Confidentiality and anonymity was assured.

Study nurses have the right to refuse to participate and or withdraw from the study without any rational any time.

Study nurses privacy was considered during collection of data.

\section{Statistical analysis of data}

The data obtained had reviewed, prepared for computer entry, coded, analyzed and tabulated. Descriptive statistics (frequencies and percentages, mean and standard deviation, i.e.) were done using computer program (SPSS) version(22). Chi-square and One-way-ANOVA tests used in relationship between Assiut university and Al Eman Algadida hospitals' knowledge and practice. It's considered significant when $\mathrm{P}$. value less than (0.05).

\section{Results}

Part I: Sociodemographic data for nurses

Table (1): Distribution of the study nurses according to sociodemographic characteristics of the studied nurses: $(n=45)$.

\begin{tabular}{|c|c|c|c|c|}
\hline \multirow{2}{*}{ Items } & \multicolumn{2}{|c|}{ Main Assiut university hospital } & \multicolumn{2}{|c|}{ Al EmanAlgadida hospital } \\
\hline & No. $(n=30)$ & $\%$ & No. $(n=15)$ & $\%$ \\
\hline \multicolumn{5}{|l|}{ Gender } \\
\hline Male & 1 & 3.3 & 3 & 20.0 \\
\hline Female & 29 & 96.7 & 12 & 80.0 \\
\hline \multicolumn{5}{|l|}{ Age: (years) } \\
\hline $18>30$ & 16 & 53.3 & 11 & 73.3 \\
\hline $30>40$ & 13 & 43.3 & 4 & 26.7 \\
\hline $40>50$ & 1 & 3.3 & 0 & 0.0 \\
\hline $50 \&$ more & 0 & 0.0 & 0 & 0.0 \\
\hline \multicolumn{5}{|l|}{ Workplace } \\
\hline General Surgery & 17 & 65.7 & 13 & 86.7 \\
\hline Orthopaedic & 13 & 43.3 & 2 & 13.3 \\
\hline \multicolumn{5}{|l|}{ Level of education } \\
\hline -Diploma of nursing & 19 & 63.3 & 10 & 66.7 \\
\hline -Technical of nursing & 11 & 36.7 & 5 & 33.3 \\
\hline \multicolumn{5}{|l|}{ Years of experience } \\
\hline$<5$ & 11 & 36.7 & 9 & 60.0 \\
\hline $5<10$ & 12 & 40.0 & 4 & 26.7 \\
\hline$\geq 10$ & 7 & 23.3 & 2 & 13.3 \\
\hline \multicolumn{5}{|l|}{ Attending training courses: } \\
\hline Yes & 19 & 63.3 & 6 & 40.0 \\
\hline No & 11 & 36.7 & 9 & 60.0 \\
\hline \multicolumn{5}{|l|}{ Number of training courses } \\
\hline One & 17 & 56.7 & 5 & 33.3 \\
\hline Two & 0 & 0.0 & 0 & 0.0 \\
\hline Three & 1 & 3.3 & 0 & 0.0 \\
\hline -Four \& more & 1 & 3.3 & 1 & 6.7 \\
\hline
\end{tabular}


Table (2): distribution of the study nurses related to medical investigation and vaccine history $(n=45)$

\begin{tabular}{|c|c|c|c|c|}
\hline \multirow{2}{*}{ Items } & \multicolumn{2}{|c|}{ Main Assiut university hospital $(n=30)$} & \multicolumn{2}{|c|}{ Al EmanAlgadida hospital $(n=15)$} \\
\hline & No & $\%$ & No & $\%$ \\
\hline \multicolumn{5}{|l|}{ Medical investigation } \\
\hline Yes & 6 & 20.0 & 5 & 33.3 \\
\hline No & 24 & 80.0 & 10 & 66.7 \\
\hline \multicolumn{5}{|c|}{ Type of medical investigation } \\
\hline Hepatitis & 2 & 6.7 & 3 & 20.0 \\
\hline AIDS & - & - & - & - \\
\hline Tuberculosis & - & - & - & - \\
\hline Hepatitis and AIDS & 1 & 3.3 & - & - \\
\hline Hepatitis and Tuberculosis & 0 & 0.0 & 1 & 6.7 \\
\hline All of the above & 3 & 10.0 & 1 & 6.7 \\
\hline Nothing & 24 & 80.0 & 10 & 66.7 \\
\hline \multicolumn{5}{|c|}{ Date of last medical investigation } \\
\hline Month ago & 1 & 3.3 & 1 & 6.7 \\
\hline 6 months ago & 0 & 0.0 & 0 & 0.0 \\
\hline Year ago & 5 & 16.7 & 4 & 16.7 \\
\hline \multicolumn{5}{|l|}{ Have you been vaccinated } \\
\hline Yes & 21 & 70.0 & 11 & 73.3 \\
\hline No & 9 & 30.0 & 4 & 26.7 \\
\hline \multicolumn{5}{|l|}{ Type of vaccine } \\
\hline Hepatitis & 21 & 70.0 & 10 & 66.7 \\
\hline Tuberculosis & 0 & 0.0 & 0 & 0.0 \\
\hline All of the above & 0 & 0.0 & 1 & 6.7 \\
\hline Not vaccinated & 9 & 30.0 & 4 & 26.7 \\
\hline
\end{tabular}

Table (3): Distribution of the study nurses knowledge about the hand washing and scrubbing, wearing gown and wearing the surgical gloves in operating room in both hospitals $(n=45)$.

\begin{tabular}{|c|c|c|c|c|c|c|c|c|c|c|c|c|}
\hline \multirow{4}{*}{ Items } & \multicolumn{6}{|c|}{ Main Assiut university hospital (n=30) } & \multicolumn{6}{|c|}{ Al EmanAlgadida hospital. (n=15) } \\
\hline & \multicolumn{4}{|c|}{ Correct } & \multirow{2}{*}{\multicolumn{2}{|c|}{ Incorrect }} & \multicolumn{4}{|c|}{ Correct } & \multirow{2}{*}{\multicolumn{2}{|c|}{ Incorrect }} \\
\hline & \multicolumn{2}{|c|}{ Complete } & \multicolumn{2}{|c|}{ Incomplete } & & & \multicolumn{2}{|c|}{ Complete } & \multicolumn{2}{|c|}{ Incomplete } & & \\
\hline & No. & $\%$ & No. & $\%$ & No. & $\%$ & No. & $\%$ & No. & $\%$ & No. & $\%$ \\
\hline \multicolumn{13}{|l|}{ b Hand washing and scrubbing } \\
\hline $\begin{array}{l}\text { 29- The aim of surgical hand scrub with disinfecting } \\
\text { agent. }\end{array}$ & 22 & 73.3 & 5 & 16.7 & 3 & 10.0 & 4 & 26.7 & 9 & 60.0 & 2 & 13.3 \\
\hline $\begin{array}{l}\text { 30-It necessary the health team commitment to wash } \\
\text { hands. }\end{array}$ & 29 & 96.7 & 1 & 3.3 & - & - & 14 & 93.3 & 1 & 6.7 & - & - \\
\hline 31-Steps preparing hand washing. & 28 & 93.3 & 2 & 6.7 & - & - & 11 & 73.3 & 4 & 26.7 & - & - \\
\hline 32-Take off the jewellery when washing hands. & 27 & 90.0 & 3 & 10.0 & - & - & 8 & 53.3 & 6 & 40.0 & 1 & 6.7 \\
\hline $\begin{array}{l}\text { 33-Period of surgical hand scrub before participating } \\
\text { in operations }\end{array}$ & 29 & 96.7 & - & - & 1 & 3.3 & 14 & 93.3 & - & 0.0 & 1 & 6.7 \\
\hline $\begin{array}{l}34 \text { Preparing steps for surgical hand scrub before } \\
\text { surgery. }\end{array}$ & 23 & 76.7 & 2 & 6.7 & 5 & 16.7 & 4 & 26.7 & 8 & 53.3 & 3 & 20.0 \\
\hline $\begin{array}{l}\text { 35-Parts that should give most attention during } \\
\text { surgical hand scrub. }\end{array}$ & 29 & 96.7 & 1 & 3.3 & - & - & 15 & 100 & - & - & - & - \\
\hline 36- Necessary drying hands thoroughly after washing. & 28 & 93.3 & - & - & 2 & 6.7 & 14 & 93.3 & - & - & 1 & 6.7 \\
\hline 37-Importance of drying hands after washing. & 26 & 86.7 & 2 & 6.7 & 2 & 6.7 & 10 & 66.7 & 5 & 33.3 & - & - \\
\hline \multicolumn{13}{|l|}{ c-Wearing sterile gown in operations } \\
\hline 38- Steps used when you wearing sterile gown. & 27 & 90.0 & 1 & 3.3 & 2 & 6.7 & 8 & 53.3 & 1 & 6.7 & 6 & 40.0 \\
\hline \multicolumn{13}{|l|}{ d-Wearing the sterile gloves } \\
\hline 39-Surgical team wearing sterile gloves in this times. & 30 & 100.0 & - & - & - & - & 12 & 80.0 & 3 & 20.0 & - & - \\
\hline 40-Principles wearing the surgical gloves. & 28 & 93.3 & 1 & 3.3 & 1 & 3.3 & 8 & 53.3 & 5 & 33.3 & 2 & 13.3 \\
\hline $\begin{array}{l}\text { 41-It is necessary to wash hands thoroughly after take } \\
\text { off glove. }\end{array}$ & 30 & 100.0 & - & - & - & - & 14 & 93.3 & 1 & 6.7 & - & - \\
\hline
\end{tabular}


Table (4): Distribution of the study nurses practice regarding cleaning, disinfection and sterilization of surgical instrument in operating room in both hospitals: $(n=45)$.

\begin{tabular}{|c|c|c|c|c|c|c|c|c|c|c|c|c|c|c|c|}
\hline \multirow{4}{*}{ Items } & \multicolumn{7}{|c|}{ Main Assiut university hospital $(n=30)$} & \multicolumn{7}{|c|}{ Al EmanAlgadida hospital (n=15) } & \multirow{4}{*}{$P$ value } \\
\hline & \multicolumn{4}{|c|}{ Done } & \multirow{2}{*}{\multicolumn{2}{|c|}{ ND }} & \multirow{3}{*}{ Mean \pm SD } & \multicolumn{5}{|c|}{ Done } & \multirow{2}{*}{\multicolumn{2}{|c|}{$\begin{array}{c}\text { ND } \\
\text { Mean } \pm \text { SD }\end{array}$}} & \\
\hline & \multicolumn{2}{|c|}{ Co } & \multirow{2}{*}{\multicolumn{2}{|c|}{\begin{tabular}{|l|l|}
\multicolumn{1}{|c|}{ Inc } \\
No & $\%$ \\
\end{tabular}}} & & & & \multicolumn{2}{|c|}{ Co } & \multicolumn{3}{|c|}{ Inc } & & & \\
\hline & No. & $\%$ & & & No. & $\%$ & & No. & $\%$ & & \begin{tabular}{l|l} 
No & \\
\end{tabular} & $\%$. & No & $\%$ & \\
\hline $\begin{array}{l}\text { IV- Cleaning: } \\
\text { 85-Wear personnel protective } \\
\text { equipment. }\end{array}$ & 1 & 3.3 & 29 & 96.7 & - & - & $1.9 \pm 0.1$ & - & - & 15 & 100.0 & - & - & $2.0 \pm 0.0$ & 0.486 \\
\hline $\begin{array}{l}\text { 86-Rinse the equipment with } \\
\text { cold water. }\end{array}$ & 30 & 100.0 & - & - & - & - & $1.0 \pm 0.0$ & 13 & 86.7 & 2 & 13.3 & - & - & $1.1 \pm 0.3$ & $0.042 *$ \\
\hline 87-Soak the equipment in warm & 2 & 6.7 & 3 & 10.0 & 25 & 83.3 & $2.7 \pm 0.5$ & - & - & - & - & 15 & 100. & $3.0 \pm 0.0$ & 0.121 \\
\hline $\begin{array}{l}\text { 88-Cleanse the equipment } \\
\text { thoroughly with stiff brush and } \\
\text { detergent. }\end{array}$ & 2 & 6.7 & 1 & 3.3 & 27 & 90.0 & $2.8 \pm 0.5$ & - & - & - & - & 15 & 100. & $3.0 \pm 0.0$ & 0.233 \\
\hline $\begin{array}{l}\text { 89-Rinse the equipment in } \\
\text { warm water. }\end{array}$ & 29 & 96.7 & - & - & 1 & 3.3 & $1.1 \pm 0.3$ & 13 & 86.7 & 2 & 13.3 & - & - & $1.1 \pm 0.3$ & 0.562 \\
\hline $\begin{array}{l}\text { 90-Dry the equipment with } \\
\text { clean material. }\end{array}$ & 2 & 6.7 & 3 & 10.0 & 25 & 83.3 & $2.7 \pm 0.5$ & - & - & 2 & 13.3 & 13 & 86.7 & $2.8 \pm 0.3$ & 0.537 \\
\hline $\begin{array}{l}\text { 91-Cleanse the used brush, } \\
\text { gloves. }\end{array}$ & 2 & 6.7 & 3 & 10.0 & 25 & 83.3 & $2.7 \pm 0.5$ & - & - & 2 & 13.3 & 13 & 86.7 & $2.8 \pm 0.3$ & 0.537 \\
\hline $\begin{array}{l}\text { 92-Remove gloves and plastic } \\
\text { apron . }\end{array}$ & 11 & 36.7 & 18 & 60.0 & 1 & 3.3 & $1.6 \pm 0.5$ & 2 & 13.3 & 12 & 80.0 & 1 & 6.7 & $1.9 \pm 0.4$ & 0.112 \\
\hline 93-Wash hand. & 10 & 33.3 & 19 & 63.3 & 1 & 3.3 & $1.7 \pm 0.5$ & - & - & 15 & 100.0 & - & - & $2.0 \pm 0.0$ & $0.036^{*}$ \\
\hline $\begin{array}{l}\text { 94-Store clean equipment in } \\
\text { clean labelled container. }\end{array}$ & 29 & 96.7 & 1 & 3.3 & - & - & $1.1 \pm 0.1$ & 10 & 66.7 & 5 & 33.3 & - & - & $1.3 \pm 0.4$ & $0.004 * *$ \\
\hline $\begin{array}{l}\text { V- Disinfecting equipment } \\
\text { (Cidex): } \\
\text { 95-Identify equipment need } \\
\text { high level of disinfection by } \\
\text { chemicals. }\end{array}$ & 15 & 50.0 & - & - & 15 & 50.0 & $2.5 \pm 1.5$ & 13 & 86.7 & 2 & 13.3 & - & - & $1.1 \pm 0.3$ & $0.001 * *$ \\
\hline $\begin{array}{l}\text { 96-Prepare fresh solution of } \\
\text { glutaradehyde } 2 \% \text { (Cidex). }\end{array}$ & 14 & 46.7 & 1 & 3.3 & 15 & 50.0 & $2.5 \pm 1.5$ & 13 & 86.7 & 2 & 13.3 & - & - & $1.1 \pm 0.3$ & $0.001 * *$ \\
\hline $\begin{array}{l}\text { 97-Immerse cleaned and dried } \\
\text { items in cidex. }\end{array}$ & 13 & 43.3 & 2 & 6.7 & 15 & 50.0 & $2.5 \pm 1.4$ & 7 & 46.7 & 8 & 53.3 & - & - & $1.5 \pm 0.4$ & $0.012 *$ \\
\hline 98-Cover container and soak. & 1 & 3.3 & 14 & 46.7 & 15 & 50.0 & $2.9 \pm 1.1$ & 1 & 6.7 & 12 & 80.0 & 2 & 13.3 & $2.1 \pm 0.4$ & $0.003 * *$ \\
\hline $\begin{array}{l}\text { 99-Soak equipment for } 10 \\
\text { hours . }\end{array}$ & 1 & 3.3 & 14 & 46.7 & 15 & 50.0 & $2.9 \pm 1.1$ & - & - & 12 & 80.0 & 3 & 20.0 & $2.2 \pm 0.4$ & $0.011 *$ \\
\hline $\begin{array}{l}\text { 100-Avoid adding any other } \\
\text { item. }\end{array}$ & 4 & 13.3 & 11 & 36.7 & 15 & 50.0 & $2.8 \pm 1.1$ & - & - & 12 & 80.0 & 3 & 20.0 & $2.4 \pm 0.4$ & $0.043 *$ \\
\hline 101-Remove items from cidex. & 12 & 40.0 & 3 & 10.0 & 15 & 50.0 & $2.6 \pm 1.4$ & 3 & 20.0 & 12 & 80.0 & - & - & $1.8 \pm 0.4$ & $0.044 *$ \\
\hline 102- Rinse items thoroughly . & 11 & 36.7 & 4 & 13.3 & 15 & 50.0 & $2.6 \pm 1.4$ & 4 & 26.7 & 11 & 73.3 & - & - & $1.7 \pm 0.4$ & $0.022 *$ \\
\hline 103- Use items immediately. & 15 & 50.0 & - & - & 15 & 50.0 & $2.5 \pm 1.5$ & 4 & 26.7 & 11 & 73.3 & - & - & $1.7 \pm 0.4$ & 0.065 \\
\hline $\begin{array}{l}\text { 104-Handle items with sterile } \\
\text { gloves . }\end{array}$ & 15 & 50.0 & - & - & 15 & 50.0 & $2.5 \pm 1.5$ & 7 & 46.7 & 8 & 53.3 & - & - & $1.5 \pm 0.5$ & $0.022 *$ \\
\hline
\end{tabular}

Table (5): Percentage distribution of nurses' knowledge about the principle of infection control in operating room in both hospitals $(n=45)$.

\begin{tabular}{|c|c|c|c|c|}
\hline \multirow{2}{*}{ Nurses' knowledge } & \multicolumn{2}{|c|}{ Main Assiut university hosp } & \multicolumn{2}{|c|}{ Al EmanAlgadida hospital } \\
\hline & No. & $\%$ & No. & $\%$ \\
\hline Poor $\quad(<=50 \%)$ & - & - & - & - \\
\hline Fair $\quad(51 \%$ to $70 \%)$ & - & - & - & - \\
\hline Good $\quad(71 \%$ to $100 \%)$ & 30 & 100.0 & 15 & 100.0 \\
\hline Total & 30 & 100.0 & 15 & 100.0 \\
\hline
\end{tabular}


Fig. (1): Comparison of nurses basic practice of infection control at both hospitals.

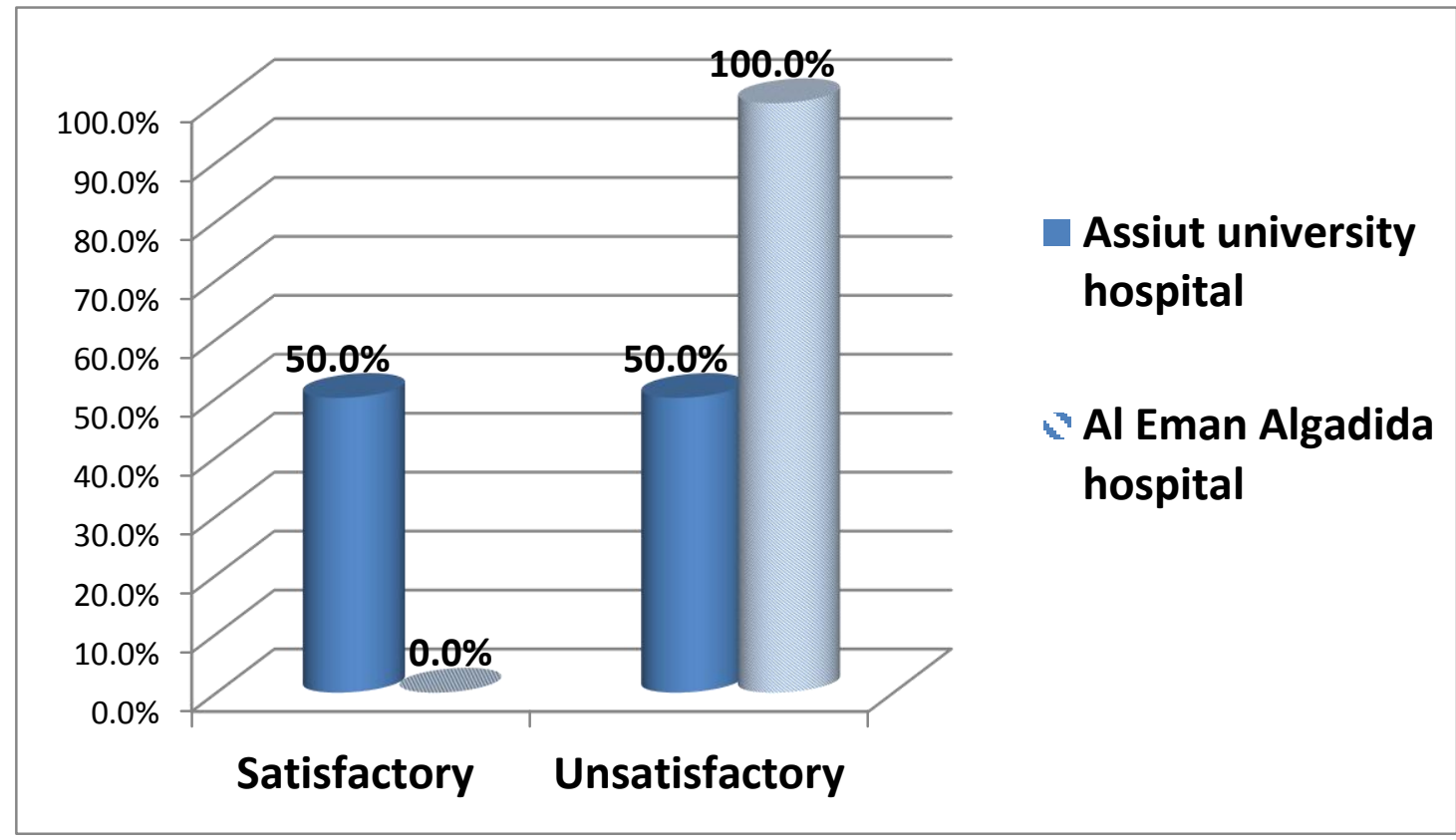

Table (1): This table shows that; The majority of nurses are female at both main Assiut and AL Eman hospitals $(96.7 \%, 80 \%$ respectively). More than half of nurses their age ranged from 18>30 years in both hospitals $(53.3 \%, 73.3 \%$ respectively). Most of nurses had diploma of nursing $(63.3 \%, 66.7 \%$ respectively). More than half of nurses (63.3\%) had attended training programs at main Assiut hospital while more than one third of nurses in Al Eman Algadida had attended training programs (40\%). The distribution of the nurses according to Workplace the majority of nurses at both main Assiut and Al Eman hospitals work in general Surgery $(65.7 \%, 86.7 \%$ respectively). More than half of nurses in $\mathrm{Al}$ Eman-Algadida hospital nurses $(60.0 \%)$ their years of experience less than 5 years, while at main Assiut University hospital (40.0\%) their years of experience from $5<10$ years.

Table (2): Illustrates that, majority of nurses hadn't medical investigation through work in both main Assiut and ALEman hospitals (80.0\%, 66.7\% respectively). As regard types of medical investigation less than one third in both hospitals had hepatitis investigation $(6.7 \%, 20.0 \%)$ respectively. Two third of nurses had been vaccinated $(70.0 \%$, $73.3 \%$ respectively).

Table (3): This table show that; This table show that; Majority of nurses had complete correct answer for items b,c and d at both hospitals.

Table (4): This table show that : that: As regard cleaning most of nurses at both both hospitals had not done in items 87, 90 and 91 . There are significant statistical difference in all items $\mathrm{V}$ of disinfecting equipment in both hospitals.

Table (5) : Reflected that; All of nurses had good knowledge about the principles of infection control in operating room at main Assiut and AlEman Algadida hospitals (100.0\%).

Fig (1) : This figure reflected that; all nurses of AL EmanAlgadida hospital had unsatisfactory level in executing practice of the principle of infection control in operating room with percentage $(100 \%)$. While half of Main Assiut university hospital had unsatisfactory level with percentage $(50 \%)$. There is significance statically difference with $\mathrm{p}$ value $0.042 *$

\section{Discussion}

The present study aims to assess of nurse's preformance regarding infection control in operating room at main Assiut University and AlEman Algadida hospital.

Regarding characteristics of the studied nurses

The present study revealed that more than two third are female at both Main Assiut and ALEman Algadida hospitals. This result agrees with Malan (2009). Labrague, et al., (2012) which reported that, the two third are females.

This finding due to the fact that This finding due to majority employed in nursing field from females. recently there is increased in the number of male which working in nursing field. The finding of the present study revealed that, more than half of nurses their age ranged from $18>30$ years at Main Assiut 
university hospitals and more than two third at AlEman Algadida hospitals, according to the years of experience, it was found that less than half of them have an experience less than 5 years and half of nurses had diploma nursing education in both hospitals. This finding agree with Khalifa, ( 2011) who reported that more than half of nurses' were less than twenty five years old, less than half of them have an experience less than 5 years.

Also, the finding of the present study show that, more than half of nurses had attended training programs at Main Assuit University hospital, while more than one third of nurses at Al Eman Algadida had attended training programs. This finding agree with Khalifa, (2011) who reported that, less than half the nurses included in the study haven't training courses, even whose attending training courses minor of them attending training courses related to infection control This finding agree with Alaaa-Eldeen et al., ( 2012) who reported that the majority of nurses had no training programs related to anesthesia and patient safety, according to Marquis \& Huston, (2009) stated that the education and training are two components of staff development. The better trained and more competent the staff, the fewer staff required, which in turn saves the organization money and raise reproductively.

This finding revealed that majority of nurses had complete correct answer for knowledge about infection control in both hospitals agree with Labrague, et al., (2012) which referred that more than half of nurses of the respondents "excellent", while $38.09 \%$ scored very good.

According to Goodman \& Spry, (2014) who reported that all instruments and devices intended to penetrate a mucous membrane must be a sterilization. While all instruments and devices intended to contract but not penetrates an intact mucous membrane must be at least high level disinfected. Vajpayee, (2005). Who mentioned that all instruments must be inspected for cleanliness and proper functioning before placing in a tray or wrapper.

As regarding the nurse's knowledge about the hand washing and scrubbing, wearing gown and wearing the surgical glove in operating room in both hospitals This finding reported that, give correct answer about hand washing, this disagreement with Hassan et al., (2011). who mentioned that one third of the nurses incorrectly answered the question about the proper routine and surgical hand washing, half of nurses at Main Assiut University hospital and one third of nurses at Al Eman Algadida hospital give correct answer about the need to wash hands after take-off glove. According to Goodman \& Spry, (2014) stated that, hand hygiene is often considered the single most important step in preventing infection. Operating room personnel like all health care personnel should perform hand hygiene before and after patient contact before donning gloves and after removing gloves.

Rosdahl and Kowalski, (2008) recommend that perform hand washing in the following situations; when hands are visibly soiled, before and after contacts with all clients, after contact with any sources of microorganisms e.g blood or body fluids, mucous membrane, non intact skin or objects that might be contaminated, before and after performing invasive procedures and before removing gloves. According to Rosdahl \& Kowalski, (2008) who stated that use of gloves does not eliminate the need for careful frequent hand washing.

In this study result revealed that most nurses not done dry hands, this disagree with Gregory \& Mursell (2010) who stated that, The proper drying of hands should be an essential component of effective hand hygiene procedures.

As regarding personal protection wearing mask at both hospitals, the study result mentioned that there is no significant statistical difference between both hospitals in wearing mask, these result disagree with Malan, (2009) which reported that two third know how to wear the mask and less than one third wore the mask incorrectly.

As regarding nurses removing mask and boot in operating room at both hospitals the result revealed that majority of nurses at both hospitals incorrectly removing mask. There is significant statistical difference in discard the mask. Burton \& Ludwig., (2014) stated that the correct order to remove, the mask prevent contamination of surfaces. According to Gibson \& Shah, (2012), stated that correct removal of personal protective equipment protect medical assistant from exposure to contaminated materials and limits opportunities for selfcontamination.

Regarding the nurses performance, all nurses of AL Eman Algadida hospital had unsatisfactory level of practices of the principles of infection control in operating room. While half at Assiut University hospital had unsatisfactory level. This finding disagree with Kabir, (2010). which reported that the nurses had low level of knowledge and high level of practice.

The present study revealed that total score's of nurses knowledge and practice who working in operating room at Main Asuuit university hospital better than those who working at Al Eman Algadida hospital this may because nurses who were working in operating room at Main Assuit university hospital attended training in continuous education center, 
and nurses followed and accountable from infection control team.

\section{Conclusion}

The result concluded that nurses in operating room at both Assuit university and AlEman hospital have good knowledge regarding infection control in operating room, as regarding nurses practice all nurses at AL Eman Algadida hospital had unsatisfactory level in executing practice of the principle of infection control in operating room. While half of nurses at Assiut University hospital had unsatisfactory level of practice.

\section{Recommendations}

- Continued nursing education training programs in operating room at both Assiut university and $\mathrm{Al}$ Eman Algadida hospitals should be organized equipped with the necessary educational facilities and materials necessary to upgrade the knowledge and skills of practicing nurses, about infection control knowledge and practice.

- Coordination between Al Eman Algadida hospital and University hospital to share training program

- All nurses of operating room should be receive vaccination before started work in operating room and serologic testing for $\mathrm{HBV}, \mathrm{HCV}, \mathrm{HIV}$ every 6 month.

- Activating the role of infection control team to monitor and correct performance of the nurses in the operating.

\section{References}

1. Alaa.Eldeen T.., Saad A., \& Eid H., (2012): General Nursing Measures implemented For Control \& Prevention of Nosocomial Infection in The General. Journal of American Science. Volume 8 (9), Pp.945- 957.

2. Burkitt H., Deakin P., Quick C., Raftery A., Joanna B., \& Reed J., (2007) : Essential surgery : problems, diagnosis, and management. 4th ed. Chapter, principles of asepsis, Edinburgh, Pp.144.

3. Burton M., \& Ludwig L., (2014): Fundamentals of Nursing Care: Concepts, Connections \&Skills ,chapter 14,medical asepsis and infection control, chapter 22, surgical asepsis, F.A. Davis, USA, Pp.264, 458.

4. Daman N., (2012): Manual of Infection Prevention and Control. 3rd ed, chapter 15, surgical site infection, Oxford University Press, Pp. 290.
5. DeLaune S., \& Ladner P., (2010): Fundamentals of Nursing.4th ed, chapter 29, safety, infection control and hygiene, Cengage Learning, USA, Pp. 659.

6. Gibson J., \& Shah B., (2012): Clinical Medical Assisting: An Introduction to the Fundamentals of Practice. Chapter 5, infection control medical asepsis, Jones \& Bartlett Publishers,Pp. 128.

7. Goodman T., \& Spry C., (2014): Essentials of Perioperative Nursing. $5^{\text {th }}$ ed, chapter 5, prevention of infection Aseptic practices, chapter 4 , preparation of instruments and items used in surgery, cleaning, packaging and storage, Jones \& Bartlett Publishers, Pp.101,116, 95, 70-77.

8. Gregory P., \& Mursell M., (2010): Manual of Clinical Paramedic Procedures, chapter 12, infection control, John Wiley \& Sons, Pp.231.

9. Hassan A., Hassan M., Abdrahman A., Elshallaly G., \& Saleh M., (2011): Assessment of existing practices in the operating theatre in the Khartoum North Teaching Original Research: Assessment of operating theatre practices in a teaching hospital in Sudan Hospital,Pp. 79:82.

10. Holland K., (2012): Placement Learning in Surgical Nursing, A guide for students in practice, 1: Placement Learning in Surgical Nursing. Chapter 2, introduction to the principles of surgical nursing, in Elsevier Health Sciences.Pp. 25.

11. Kabir H., (2010) : Nurses knowledge and practice regarding prevention of surgical site infection in Bangladesh. Master thesis, prince of songkla university, Pp. 53-61.

12. Khalifa H., (2011) : Assessment of nurse's performance regarding reducing or prevention of nosocomial infection for patients with cancer /suggested nursing, master degree in medical surgical nursing, faculty of nursing, Assiut University, Pp.50-60.

13. Labrague L., Arteche D., Yboa B., \& Pacolor N., (2012) : Operating Room Nurses' Knowledge and Practice of Sterile Technique. Journal Nurse Care. Volume 1(4), Pp.1-5.

14. Malan K., (2009): Regestrated nurse's knowledge of infection technique principles in the control and sterile operating room complex of private hospital. Master thesis in the faculty of the health science At the Nelson manila metropolitan University, Pp. 64-70.

15. Marquis L., Bessie \& Huston J., Carol., (2009) : Leadership roles \& management functions in nursing, 6th ed, Lippincott, Hong Kong, Pp.371. 
16. Osborn K., Wraa C., \& Waston A., (2010): medical surgical nursing. Medical Surgical Nursing Preparation for Practice, Volumes 1 \& 2: Include Pearson Etex, chapter 26, operating room, Prentice Hall PTR, USA. Pp. 621.

17. Rosdahl C., \& Kowalski M., (2008): Textbook of Basic Nursing. 9th ed, chapter 41, medical asepsis, chapter 57 , surgical asepsis, Lippincott Williams \& Wilkins, Pp. 442,743.

18. Schlossberg D., (2008) : Clinical Infectious Disease, Chapter 112, Surgical Prophylaxis Cambridge University Press, Pp.797.

19. Spry S., (2009): Essentials of Perioperative Nursing. 4th ed, chapter 3, prevention of infection -preparation of instruments and items used Jones \& Bartlett Learning, USA, Pp. 33.

20. Vajpaye E., (2005) : Phacoemulsification Surgery, chapter 8, sterilization of operation theatre and surgical equipment's, Jaypee Brothers Publishers, Pp.76. 